\title{
Effect of the Tc13Tul antigen from Trypanosoma cruzi on splenocytes
}

\section{from naïve mice}

Laura Mónica Tasso ${ }^{1 *}$, Andrea Cecilia Bruballa ${ }^{1 \text { 1**}^{*}}$, Patricia Andrea Garavaglia ${ }^{1}$, Mónica Inés Esteva ${ }^{1}$, María Cecilia Albareda ${ }^{1}$, Gabriela Andrea García ${ }^{1 \S}$

${ }^{1}$ Instituto Nacional de Parasitología (INP) “Dr. Mario Fatala Chaben”-ANLIS “Dr. Carlos G. Malbrán", Buenos Aires, Argentina.

\#Present address: Instituto de Medicina Experimental (IMEX)-Consejo Nacional de Investigaciones Científicas y Técnicas (CONICET), Buenos Aires, Argentina.

* These authors contributed equally to this work.

${ }^{\S}$ Corresponding author (G.A. García): INP “Dr. Mario Fatala Chaben”, Paseo Colón 568, Buenos Aires (1063), Argentina. Tel.:+541143312330; fax:+541143317142. E-mail: gaandgarcia@yahoo.com.

RUNNING TITLE: Effect of Tc13Tul on nä̈ve splenocytes 


\section{ABSTRACT}

Trypanosoma cruzi, the etiological agent of Chagas disease, releases factors, including antigens from the trans-sialidase (TS) superfamily, which modulate the host immune responses. Tc13 antigens belong to group IV of TSs and are characterized by C-terminal EPKSA repeats. Here, we studied the effect of the Tc13 antigen from the Tulahuén strain, Tc13Tul, on primary cultures of splenocytes from naïve BALB/c mice. Recombinant Tc13Tul increased the percentage of viable cells and induced B (CD19+) lymphocyte proliferation. Tc13Tul stimulation also induced secretion of non-specific IgM and interferon-gamma (IFN- $\gamma)$. The same effects were induced by $T c 13 \mathrm{Tul}$ on splenocytes from naïve $\mathrm{C} 3 \mathrm{H} / \mathrm{HeJ}$ mice. In vivo administration of $T c 13 \mathrm{Tul}$ to nä̈ve $\mathrm{BALB} / \mathrm{c}$ mice increased non-specific IgG in sera. In addition, in vitro cultured splenocytes from Tc13Tul-inoculated mice secreted a higher basal level of non-specific $\operatorname{IgM}$ than controls and the in vitro Tc13Tul stimulation of these cells showed an enhanced effect on IgM and IFN- $\gamma$ secretion. Our results indicate that $T c 13$ Tul may participate in the early immunity in $T$. cruzi infection by favoring immune system evasion through B-cell activation and non-specific Ig secretion. In contrast, as IFN- $\gamma$ is an important factor involved in $T$. cruzi resistance, this may be considered a Tc13Tul effect in favor to the host.

KEYWORDS: Chagas disease, immune evasion, excretory secretory antigen, B lymphocyte, trans-sialidase 


\section{INTRODUCTION}

Chagas disease is an endemic parasitosis of the American continent caused by the protozoan Trypanosoma cruzi, which affects 6 million people worldwide (WHO, 2018). As a consequence of migration processes, nowadays, $T$. cruzi infection represents a health problem not only in the Americas but also in non-endemic countries (Rassi et al., 2010).

The acute phase of $T$. cruzi infection is characterized by polyclonal B-cell activation, hypergammaglobulinemia (Minoprio et al., 1998; Bryan et al., 2010; Bermejo et al., 2011) and a strong humoral response against antigenic motifs that masks key catalytic domains relevant to the infection process (Alvarez et al., 2001). Cumulative evidence has shown that T. cruzi expresses and sheds into the bloodstream immunomodulatory molecules which are involved in these events (Da Silva et al., 1998; Leguizamón et al., 1999; Reina-San-Martin et al., 2000; Ouaissi et al., 2002). Among them, antigens belonging to the trans-sialidase (TS) superfamily have been demonstrated to participate in: i- complement evasion (Beucher and Norris, 2008), ii- B-lymphocyte proliferation (Gao et al., 2002; Bermejo et al., 2013), iii- apoptosis of immune cells (Leguizamón et al., 1999; Mucci et al., 2006), ivinduction of non-neutralizing antibodies (Affranchino et al., 1989; Burns et al., 1992; Buscaglia et al., 1998) and v- evasion of protective immune responses through epitope variation (Wrightsman et al., 1994; Millar et al., 1999; Martin et al., 2006). These actions favor the delay in the generation of specific immunity, thus allowing the parasite to spread and persist in the mammalian host (Cardoso et al., 2016).

The TS superfamily is the largest $T$. cruzi gene family, encoding more than 1,400 genes classified in eight groups (Freitas et al., 2011). It is worth noting that only group I contains 
active trans-sialidases (TcTSs), which transfer sialic residues from host sialoconjugates to the parasite cell surface (Mucci et al., 2017). While TcTSs contain a Tyr $_{342}$ which is crucial in the enzyme activity, all the other members of the TS superfamily show a $\mathrm{Tyr}_{342} \mathrm{His}$ replacement (Cremona et al., 1995). These enzymatically inactive proteins (iTcTSs) retain a lectin-like activity (Cremona et al., 1999; Todeschini et al., 2002a) and it has been hypothesized that, in natural infection, they act mainly as virulence factors (Burgos et al., 2013). Tc13 antigens, which are members of group IV of the TS superfamily, have not been largely studied so far. They are characterized by bearing five amino-acid (EPKSA) repeats at their C-terminal region (Campetella et al., 1992), which elicit a strong humoral response in $T$. cruzi-infected patients and mice, especially in the acute phase of the infection (Burns et al., 1992; Peralta et al., 1994; García et al., 2008; Santamaría et al., 2013). Genetic and recombinant immunizations of $\mathrm{BALB} / \mathrm{c}$ mice with the $T c 13$ antigen of the Tulahuén strain of $T$. cruzi (Tc13Tul) have shown that $T c 13$ specific immunity does not confer protection against $T$. cruzi infection (García et al., 2006, García et al., 2008). Moreover, the high production of non-protective anti-EPKSA IgG in the acute phase of the infection, the presence of a weak anti-Tc13 memory T-cell response, and the lack of $T c 13$-specific CD4+ T-cells with ability to release IFN- $\gamma$ in the chronic phase of the infection suggest that $T c 13$ antigens are involved in mechanisms of evasion from host immunity (García et al., 2008). To test this hypothesis and obtain further information about primary immune responses triggered by $T c 13$ antigens on B and $\mathrm{T}$ lymphocytes, the aim of the present study was to evaluate the effect of $T c 13 \mathrm{Tul}$ on the viability and lymphoproliferation of splenocytes from naïve mice in vitro. We also aimed to study Tc13Tul ability to induce polyclonal Ig production and cytokine secretion by in vitro and in vivo stimulation of these cells. 


\section{MATERIALS AND METHODS}

\section{Ethical statement and Mice}

Animal studies were carried out with the approval of the Institutional Ethical Committee and conformed to the ethical treatment of animals established by the Argentinean Animal Protection Society. Six-week-old male nä̈ve mice were used in all the experiments. BALB/c mice were maintained at the animal facility of INP "Dr. Fatala Chaben" in ventilated plastic cages with free access to tap water and enough rodent food. $\mathrm{C} 3 \mathrm{H} / \mathrm{HeJ}$ mice were kindly provided by Dr. Oscar Campetella from Instituto de Investigaciones Biotecnológicas-Universidad de San Martín (IIB-UNSAM), Buenos Aires, Argentina. For euthanasia, mice were subjected to cervical dislocation under anesthesia with $100 \mu \mathrm{l}$ of a mixture of ketamine $(50 \mathrm{mg} / \mathrm{kg}$; Ketafine, Brouwer, CABA, Argentina) and xylazine (5 mg/kg; Kensol, König, Avellaneda, BA, Argentina) delivered by intraperitoneal (i.p.) injection.

\section{Recombinant proteins}

Tc13Tul protein (GenBank Accession no. AF091620) was expressed as a maltose-binding protein (MBP) fusion, purified by amylose resin and filtrated with a $100 \mathrm{kDa} \mathrm{MW}$ cut off centrifugal filter device (Centricon®, Millipore, Darmstadt, Germany) (García et al., 2003). The clone coding for EPKSA (GenBank Accession no. M92046) repeats fused to glutathione-S-transferase (GST) was kindly provided by Dr O. Campetella (IIB-UNSAM, Buenos Aires, Argentina). The GST-EPKSA recombinant protein was purified by glutathione-agarose resin. The homogeneity of the proteins was evaluated by sodium dodecyl sulfate-7.5\% polyacrylamide gel electrophoresis (SDS-7.5\% PAGE). 


\section{In vitro culture of splenocytes}

Mouse splenocytes depleted of erythrocytes were seeded in 96-well culture plates at $4 \times 10^{5}$ cells/well in $200 \mu \mathrm{l}$ of RPMI-10\% fetal bovine serum (FBS) in the presence of either

Tc13Tul $\left(6 \mu \mathrm{g} / 10^{6}\right.$ cells $)$, MBP $\left(2.2 \mu \mathrm{g} / 10^{6}\right.$ cells), EPKSA $\left(6 \mu \mathrm{g} / 10^{6}\right.$ cells $)$ or GST (1.5 $\mu \mathrm{g} / 10^{6}$ cells) and incubated at $37^{\circ} \mathrm{C}$ with $5 \% \mathrm{CO}_{2}$ for 24 to $72 \mathrm{~h}$ depending on each experiment conditions. For toll-like receptor 4 (TLR4) activation assays, lipopolysaccharide (LPS) (5 $\mu \mathrm{g} / \mathrm{ml})$ (Sigma-Aldrich, Saint Louis, MO, USA) and colistin $(10 \mu \mathrm{g} / \mathrm{ml})$ (Alficetin, Argentia, CABA, Argentina) were used.

\section{Cell viability evaluation}

Cell viability was assessed by staining with trypan blue or propidium iodide (PI). Trypan blue staining was evaluated by optical microscopy counting non-stained cells (live) in a Neubauer camera and the percentage of live cells was calculated considering the initial cell inoculum of $2 \times 10^{6}$ cells $/ \mathrm{ml}$ as $100 \%$. PI staining was analyzed by flow cytometry and the percentage of live cells (PI negative) was calculated considering the total of 20,000 events acquired as $100 \%$.

\section{Flow cytometry acquisition and analysis}

Splenocytes were acquired with a BD FACS Calibur flow cytometer (BD Biosciences, NJ, USA) and analyzed with FlowJo software (Tree Star, Ashland, OR, USA). A total of 20,000 events were acquired within a primary gating based on cell scatter properties. Lymphocytes were gated based on their forward and side scattering parameters (FSC-H vs. SSC-H). The singlets were analyzed by the use of forward scatter area vs. forward scatter height dot-plot (FSC-A vs. FSC-H) and the frequencies (\%) of CD19+ and CD3+ were 
analyzed with specific antibodies (CD19-phycoerythrin (PE), CD19-allophycocyanine (APC) or CD3-PE vs. FSC-H) (Supplementary Fig. 1). Unstained samples and single-stain samples were used as controls for subsequent software compensation using the FlowJo analysis software compensation module. Carboxyfluorescein diacetate succinimidyl ester (CFSE) proliferation assays were analyzed with the FlowJo Proliferation Tool which finds the original population ( $100 \%$ of max CFSE), models the division by looking for peaks with diminishing fluorescence and calculates the percentage of divided cells.

\section{Annexin V and propidium iodide labelling}

After $48 \mathrm{~h}$ of in vitro stimulation, splenocytes were washed, resuspended in RPMI and were double-stained for annexin V (AV)-fluorescein isothiocyanate (FITC) and PI using the "Annexin-V Apoptosis Detection Kit I" (BD Pharmingen ${ }^{\mathrm{TM}}$, San Diego, CA, USA) according to the manufacturer's instructions. Incubation of cells in the presence of phytohemagglutinin (PHA) $\left(1.25 \mu \mathrm{g} / 10^{6}\right.$ cells) were used as controls. Stained cells were analyzed by flow cytometry.

\section{CFSE proliferation and lymphocyte phenotyping assays}

To track cell division, prior to in vitro culture, splenocytes were stained with $2.5 \mu \mathrm{M}$ of CFSE at $37^{\circ} \mathrm{C}$ for $10 \mathrm{~min}$, using the CellTrace ${ }^{\mathrm{TM}}$ CFSE Cell Proliferation Kit (Life Technologies, Eugene, OR, USA). CD3 cross-linking was used as a positive control for T cell proliferation. For this control, anti-CD3 monoclonal antibody (Purified Hamster antimouse CD3e clone145-2C11, BD Pharmingen ${ }^{\mathrm{TM}}$, San Diego, CA, USA) was adsorbed to the culture plate $(10 \mu \mathrm{g} / \mathrm{ml})$ for $1 \mathrm{~h}$ at room temperature (RT) before the addition of splenocytes. After 48-72 h of in vitro stimulation, cells were collected by centrifugation and 
washed with PBS 5\% FBS. Then, cells were stained for $30 \mathrm{~min}$ on ice with anti-mouse CD19-APC and anti-mouse CD3-PE (BD Pharmingen ${ }^{\mathrm{TM}}$, San Diego, CA, USA) or antimouse CD19-PE (Thermo Fisher, Rockford, IL, USA), washed with PBS 5\% FBS and fixed with $3.6 \%$ formaldehyde for $15 \mathrm{~min}$ at RT. Fixed cells were analyzed by flow cytometry.

\section{Measurement of Ig secretion}

Total Ig and $\operatorname{IgM}$ were measured in supernatants of in vitro stimulated splenocytes and sera of inoculated mice by sandwich Enzyme-Linked ImmunoSorbent Assay (ELISA). 96-well flat bottomed plates were coated with goat anti-mouse IgG (which also reacts with the light chains of IgM and IgA) (Zymed Laboratories Inc., South San Francisco, CA, USA) $5 \mu \mathrm{g} / \mathrm{ml}$ at $4^{\circ} \mathrm{C}$ overnight. After blocking with $5 \%$ skimmed milk in PBS, plates were incubated for 1h at RT with samples $(50 \mu \mathrm{l})$ : supernatants in 2-fold serial dilutions from 1:16 to 1:128 and sera diluted 1:105. The mouse monoclonal antibody 2C5D6 (Bontempi et al., 2000) was used as quantification standard. Biotinylated goat anti-mouse IgG and biotinylated goat anti-mouse $\operatorname{IgM}$ followed by incubation with streptavidin peroxidase (Vector Labs, Burlingame, CA, USA) were used to detect total $\operatorname{Ig}$ and $\operatorname{IgM}$, respectively. Color was developed with o-phenylenediaminedihydrochloride (OPD) and optical density (OD) was read at $490 \mathrm{~nm}$ using an ELISA microplate reader BioTek EL 808 (BioTek Instruments, Winooski, VT, USA).

For detecting anti-Tc13Tul and MBP-specific antibodies, plates were coated with MBP or Tc13Tul $5 \mu \mathrm{g} / \mathrm{ml}(50 \mu \mathrm{l})$ at $4^{\circ} \mathrm{C}$ overnight and the above protocol was followed from the 
blocking step onwards. Supernatants and sera were tested in a dilution of 1:2 and 1:100, respectively.

\section{Measurement of cytokine secretion}

Supernatants of stimulated splenocytes were assayed for cytokine secretion by sandwich ELISA using the OptEIA ${ }^{\mathrm{TM}}$ Set for mouse interleukin 4 (IL-4) and IFN- $\gamma$ (BD Biosciences, San Jose, CA, USA) and the mouse IL-17A (homodimer) ELISA Ready-SET-Go!@ (eBiosiences, San Diego, CA, USA) according to the manufacturer's instructions.

\section{Tc13Tul binding assays to splenocytes}

Splenocytes were incubated for $30 \mathrm{~min}$ at $4^{\circ} \mathrm{C}$ with FITC-conjugated Tc13Tul or MBP (50 $\mu \mathrm{g} / \mathrm{ml})$. After binding assay, lymphocyte phenotyping was performed by staining with antimouse CD19-PE (Thermo Fisher, Rockford, IL, USA) and anti-mouse CD3-PE (BD Pharmingen ${ }^{\mathrm{TM}}$, San Diego, CA, USA). Finally, cells were washed with PBS 5\% FBS and fixed with $3.6 \%$ formaldehyde for $15 \mathrm{~min}$ at RT. Fixed cells were analyzed by flow cytometry.

\section{Studies of Tc13Tul effects in vivo}

Six-week-old male nä̈ve BALB/c mice were inoculated intraperitoneally (i.p.) with a daily dose of $1 \mu \mathrm{g} / \mathrm{mouse} /$ dose in PBS of Tc13Tul or MBP for three days. A control group was injected with the vehicle PBS. Sera were collected prior to inoculation and on days 4, 8 y 11 after the first inoculation from the facial vein. Eleven days after the first inoculation mice were sacrificed and splenocytes were collected to be cultured in vitro. 


\section{Statistical analysis}

Data are expressed as means + standard error (SE) and were derived from at least duplicate observations per experiment. All experiments were repeated at least twice. Differences among groups were evaluated by one- or two- way analysis of variance (ANOVA), as appropriate, followed by Bonferroni as post-test. Data were analyzed using GraphPad Prism 5.0 software (Graph Prism, San Diego, CA) and differences were considered significant when the $p$ value was $<0.05$.

\section{RESULTS}

\section{Tc13Tul increases the viability of in vitro cultured splenocytes from BALB/c naïve mice} and affects their lymphocyte population

To evaluate primary immune responses triggered by $T c 13 \mathrm{Tul}$, primary splenocytes from naïve BALB/c mice were incubated for $24 \mathrm{~h}, 48 \mathrm{~h}$ and $72 \mathrm{~h}$ with recombinant $T c 13 \mathrm{Tul}$ or EPKSA repeats and cell viability was assessed by exclusion of trypan blue staining. As Tc13Tul and EPKSA are fused to MBP and GST, respectively, incubation with these carrier proteins, in equivalent amounts to those present in the respective fusion proteins, was used to rule out their basal effects. Splenocytes cultured in the absence of stimulus (RPMI) and in the presence of the mitogen compound phytohemagglutinin (PHA) were used as negative and positive controls, respectively. Splenocyte viability decreases over time because lymphocytes are incapable of dividing unless they are stimulated by a mitogen (Sharon and Lis, 2004). Similarly to PHA, incubation with Tc13Tul showed a higher number of viable cells than controls. The effect of Tc13Tul was observed as early as $24 \mathrm{~h}$ post-stimulation. Incubation with EPKSA repeats yielded a percentage of viable cells 
similar to that obtained with controls. The lack of effect with the EPKSA C-terminal portion of $T c 13 \mathrm{Tul}$ suggests that the region responsible for increasing splenocyte viability may be located at the N-terminal segment of the protein (Fig. 1A). These findings were confirmed by propidium iodide (PI) staining analyzed by flow cytometry (Supplementary Fig. 2).

To determine whether the stimulation of splenocytes with Tc13Tul induced changes in lymphocyte populations, cells stimulated for $72 \mathrm{~h}$ were subjected to flow cytometry. The analysis of side (SSC-H) vs. forward (FSC-H) scatter dot plots showed that stimulation with Tc13Tul induced a lymphocyte population of increased size and granularity (named G2), which was similar to that produced by the mitogen PHA and a CD3-specific crosslinking antibody. On the other hand, unstimulated cells or cells treated with MBP or EPKSA repeats only showed the basal lymphocyte population (named G1) (Fig. 1B). To investigate whether the G2 population was due to a lymphoproliferative effect of $T c 13 \mathrm{Tul}$, cellular proliferation of stimulated splenocytes was monitored by CFSE staining. The flow cytometry analysis of CFSE labeled-cells indicated cellular proliferation after stimulation with $T c 13$ Tul but not with EPKSA repeats or the carrier proteins. The percentage of divided cells induced by Tc13Tul was significantly higher than that induced by MBP and the EPKSA repeats (Fig. 1C). Next, to evaluate the ability of $T c 13$ Tul to induce apoptosis, stimulated splenocytes were double-stained with PI and annexin V (AV) and analyzed by flow cytometry. The analysis of quadrants AV-/PI-, AV+/PI- and AV+/PI+, performed on the lymphocyte population $(\mathrm{G} 1+\mathrm{G} 2)$, showed that stimulation with Tc13Tul, like PHA, induced an increase in the number of cells in early apoptosis (AV+/PI-) at the expense of a decrease in viable cells (AV-/PI-). According to previous results, EPKSA repeats failed to 
show this effect (Fig. 1D). These findings suggest that the increase in cell viability induced by Tc13Tul observed by trypan blue and PI staining may correspond to viable and early apoptotic cells.

Given the evidence that $T c 13$ Tul acts on the lymphocyte population, we then studied whether this antigen is able to interact with the lymphocyte surface. With this aim, binding of FITC-labeled Tc13Tul or MBP to these cells was evaluated by flow cytometry. Results showed a 2.6-fold higher labeling in the lymphocyte population with Tc13Tul-FITC than in that with MBP-FITC. To identify which lymphocyte population Tc13Tul binds to, bound cells were dyed for markers specific to B (CD19) and T (CD3) cells. Tc13Tul-FITC bound to $96.06 \%$ of CD19+ cells and to $78.73 \%$ of CD3+ cells, while the control protein MBPFITC bound to $34.6 \%$ of CD19+ and to $11.1 \%$ of CD3+ cells (Fig. 1E). These results suggest that $T c 13 \mathrm{Tul}$ interacts with surface antigens on both $\mathrm{B}$ and $\mathrm{T}$ cells.

\section{Tc13Tul induces B cell proliferation, non-specific IgM and IFN-rproduction in cultured} splenocytes from nä̈ve mice

To characterize the lymphoproliferative effect of Tc13Tul, CFSE-labeled and stimulated splenocytes were phenotyped. The CFSE profile showed that $T c 13 \mathrm{Tul}$ induced proliferation of $\mathrm{B}$ cells (CD19+) but not that of $\mathrm{T}$ cells (CD3+). Cross-linking with an anti-CD3 monoclonal antibody was used as a positive control for $\mathrm{T}$ cell proliferation, which confirms the ability of these cells to divide when an appropriate stimulus is used. In contrast, MBP stimulation showed no significant differences respect to unstimulated cells (Fig. 2A and Supplementary Fig. 3). 
Since $T c 13$ Tul stimulation induced B-lymphocyte proliferation, we next evaluated whether this effect occurred concomitantly with either non-specific or Tc13Tul-specific Ig secretion. Supernatants of $T c 13$ Tul-stimulated splenocytes showed higher total non-specific Ig levels than those of MBP-, EPKSA-, GST- or non-stimulated cells. Non-specific IgM levels were slightly lower than total Ig levels, indicating that these recombinant antigens mainly induced this Ig isotype (Fig. 2B). Tc13Tul-induced total Ig did not react with Tc13Tul and MBP by ELISA (Supplementary Fig. 4), demonstrating that these antibodies are not specific for these antigens.

To study the cytokine profile induced by Tc13Tul, the levels of IFN- $\gamma$ (Th1), IL-4 (Th2) and IL-17 (Th17) were measured in the supernatants of Tc13Tul-, MBP- and non-induced splenocytes. Neither IL-17 nor IL-4 were detected in the supernatants from MBP- and Tc13Tul-stimulated cells (Supplementary Fig. 5). In contrast, significant IFN- $\gamma$ production was detected in the supernatants of Tc13Tul-induced splenocytes. No increase in IFN- $\gamma$ was observed when cells were stimulated with recombinant EPKSA repeats (Fig. 2C).

To rule out the possibility that the increase in non-specific Ig is due to potential endotoxin (lipopolysaccharide, LPS) contamination in the Tc13Tul preparation, splenocytes were treated with antigens in the absence or presence of colistin, an agent which disrupts bacterial LPS. Colistin affected neither MBP- nor Tc13Tul-induced Ig, indicating that the level of endotoxin in these recombinant proteins has no impact on this effect. As expected, colistin neither had effect on concanavalin A-induced Ig secretion, but significantly diminished the total Ig induced by LPS (Fig. 2D). 
Tc13Tul stimulation is also observed in cultured naïve splenocytes from the LPSresistant $\mathrm{C} 3 \mathrm{H} / \mathrm{HeJ}$ mouse strain

The effect of $T c 13$ Tul on the proliferation of B cells and secretion of non-specific Ig and IFN- $\gamma$ was also observed in splenocytes from nä̈ve $\mathrm{C} 3 \mathrm{H} / \mathrm{HeJ}$ mice (Fig. 3). The particularity of the $\mathrm{C} 3 \mathrm{H} / \mathrm{HeJ}$ mouse strain is a mutation in the Toll-like receptor 4 (TLR-4), which makes it very resistant to LPS stimulation (Poltorak et al., 1998). Therefore, these results indicate that these effects are mediated by neither TLR-4 nor potential LPS contamination of recombinant proteins.

In vivo administration of Tc13Tul to nä̈ve BALB/c mice induces polyclonal Ig and IFNysecretion

To evaluate whether the effects of Tc13Tul observed in vitro are also relevant in vivo, BALB/c mice were inoculated with three doses of $T c 13 \mathrm{Tul}$ (or MBP as control) and total Ig and IgM levels were evaluated in sera on days 4, 8 and 11 after the first inoculation. Sera of the Tc13Tul-inoculated group showed increased levels of total Ig from day 8 postinoculation (Fig. 4A). IgM levels were low and remained constant throughout the measurements (Supplementary Fig. 6), suggesting that in vivo Tc13Tul stimulation may induce mainly Igs of the $\operatorname{IgG}$ isotype.

Eleven days after the inoculation, mice were sacrificed and their splenocytes were cultured in vitro for $72 \mathrm{~h}$ without stimulus (RPMI) or in the presence of MBP or Tc13Tul. Basal Ig secretion of splenocytes from $T c 13$ Tul-inoculated mice was higher than that of splenocytes from control or MBP-inoculated animals (Fig. 4B white bars). Splenocytes from MBPinoculated mice increased Ig secretion only when they were in vitro stimulated with 
Tc13Tul; however, Tc13Tul stimulation was not as high as that exerted on naïve splenocytes. This observation allowed us to speculate that the in vivo administration of MBP might have an inhibitory effect on B cells. Conversely, splenocytes from Tc13Tulinoculated mice and in vitro stimulated with Tc13Tul secreted higher Ig levels than splenocytes from naïve mice (Fig. 4B horizontal hatched bars), indicating an additive effect of in vivo and in vitro Tc13Tul administration. Splenocytes from Tc13Tul-inoculated mice also increased Ig secretion when they were in vitro stimulated with MBP (Fig. 4B vertical hatched bars). This suggests that Tc13Tul administered in vivo may have induced $\mathrm{B}$ cell activation and therefore, these cells were more reactive when in vitro stimulated also with the carrier protein MBP. The lack of Ig secretion by splenocytes from MBP-inoculated mice and in vitro stimulated with MBP validates that the one responsible for the stimulation of $\mathrm{Ig}$ production is the $T c 13 \mathrm{Tul}$ portion of the recombinant protein, and not the carrier protein. Although the evaluation of polyclonal $\operatorname{IgM}$ secretion showed a profile similar to that of total Ig, basal IgM secretion in Tc13Tul-inoculated mice was not higher than that in control groups, suggesting that Tc13Tul administered in vivo might have induced IgG rather than IgM secretion by splenocytes (Fig. 4B). It is worth mentioning that neither Tc13Tul- nor MBP-specific antibodies were detected in sera or supernatants (Supplementary Fig. 6 and 7). IFN- $\gamma$ production was only observed when splenocytes were in vitro stimulated with Tc13Tul. However, splenocytes from Tc13Tul-inoculated mice secreted higher IFN- $\gamma$ levels than splenocytes from naïve and MBP-inoculated mice, indicating that the in vivo Tc13Tul administration enhanced the effect of the in vitro Tc13Tul stimulation (Fig. 4C horizontal hatched bars).

\section{DISCUSSION}


The spleen is an important lymphoid organ that produces most of the non-specific immune responses characteristic of the acute phase of $T$. cruzi infection (Bermejo et al., 2011). Several authors have documented the involvement of the TS group I member TcTS in triggering innate and innate-like responses in this organ (Gao et al., 2002; Todeschini et al., 2002b; Bermejo et al., 2013). Our previous researches on Tc13 antigens in a BALB/c experimental model were focused on memory $T c 13$-specific immune responses. Studies of humoral and cellular responses induced by these antigens, either in the course of $T$. cruzi infection or as result of genetic and recombinant immunization with Tc13Tul antigen, suggest that the Tc13 family protein triggers mainly non-protective memory immunity (García et al., 2006; García et al., 2008). Therefore, the aim of the present work was to study primary immune responses induced by $T c 13$ antigens by evaluating their effect on splenocytes from nä̈ve mice.

All the experiments were performed with recombinant $T c 13 \mathrm{Tul}$ antigen, which is fused to MBP from E. coli. As MBP and other bacterial components have effects on innate immunity (Akira et al., 2006; Liu et al., 2017) special controls were used to avoid wrong conclusions. Purified Tc13Tul was subjected to a further filtration step to eliminate possible low-molecular-weight contaminants. MBP induced from the wild type pMalp2 vector and purified in the same conditions as that used for recombinant Tc13Tul purification was thoroughly used to rule out the effect of the carrier protein. To rule out the effect of contaminant LPS: i- control assays were performed in the presence of colistin, a cationic polypeptide which binds and neutralize the LPS molecule (Gupta et al., 2009) and ii- in vitro Tc13Tul stimulation was also evaluated in splenocytes from nä̈ve $\mathrm{C} 3 \mathrm{H} / \mathrm{HeJ}$ mice, a 
mouse strain resistant to LPS activation (Poltorak et al., 1998). Neither of these strategies abrogated the effects observed, supporting that they are Tc13Tul-induced.

Tc13Tul stimulation of nä̈ve splenocytes showed mitogenic-like effects: it increased cell viability and, in the lymphocyte population, induced proliferation as well as apoptosis. These effects were even stronger than those induced by the mitogen PHA, a lectin that binds to lymphocyte membranes (Sharon and Lis, 2004). Therefore, Tc13Tul, like PHA, induced a net increase in cell number as a result of the lymphoproliferative effect. However, after $48 \mathrm{~h}$ of stimulation, the AV/PI analysis demonstrated that a great percentage of these cells had initiated the apoptotic process. Although cell viability and apoptosis are seemingly contradictory events, it should be taken into account that early apoptotic cells $(\mathrm{AV}+/ \mathrm{PI}-)$ still maintain the integrity of the plasma membrane and, therefore, are detected as viable by techniques using dyes that are excluded from viable cells, such as trypan blue and PI. It is important to note that although the definition of the term mitogen comes from its ability to stimulate lymphocyte mitosis (Nowell et al., 2000), it is known that mitogenic stimulation also leads to Fas/FasL-mediated apoptosis, thus limiting cell expansion (Miyawaki et al., 1992; Tu et al., 2000).

In vitro stimulation with Tc13Tul of splenocytes from naïve $\mathrm{BALB} / \mathrm{c}$ and $\mathrm{C} 3 \mathrm{H} / \mathrm{HeJ}$ mice induced B cell proliferation and polyclonal IgM secretion. IgM production by Tc13Tul in vitro stimulation is consistent with the low frequency of switching from $\operatorname{IgM}$ to $\operatorname{IgG}$ secretion detected in single B cell clones after treatment with mitogenic compounds (Andersson et al., 1978). These effects were not observed when cells were stimulated with recombinant EPKSA repeats, suggesting that C-terminal repeats are not involved in these events. However, as the recombinant EPKSA used in this study belongs to the CAI strain of 
T. cruzi and has some variations respect to the EPKSA portion of Tc13Tul (García et al., 2003), it cannot be ruled out that the variations in the EPKSA units present in Tc13Tul are responsible for these effects and/or that the EPKSA portion as part of the whole Tc13 molecule has a different conformation that favours its activity. Similar studies using TcTS have indicated that the polyclonal $\mathrm{B}$ cell mitogenic activity is present in its C-terminal SAPA repeats rather than in its N-terminal domain (Gao et al., 2002). These results indicate that SAPA and EPKSA repeats might diverge in their role in early immunity, although they share other features such as immunodominance and the ability to increase the half-life of proteins in blood (Burns et al., 1992; Buscaglia et al., 1999).

Tc13Tul also induced polyclonal non-specific Ig stimulation by in vivo administration. It is worth mentioning that, based on previous studies on TcTS (Da Silva et al., 1998; Gao et al., 2002; Aridgides et al., 2013; Salvador et al., 2014), in vivo administration of Tc13Tul was carried out in the absence of any adjuvant that could mask or potentiate its effect. Tc13Tuladministerd mice showed increased non-specific IgG in sera from day 8 post-inoculation and increased total Ig secretion when their splenocytes were in vitro cultured for $72 \mathrm{~h}$. Neither of these antibodies showed specificity for Tc13Tul or MBP. Other T. cruzi antigens also failed to induce specific antibodies when administered to mice with similar protocols (Da Silva et al., 1998; Gao et al., 2002). In these studies, the lack of specific responses was ascribed to the absence of adjuvant and insufficient time to trigger antigen-specific antibodies through T-B cell interaction. These explanations can also be applied to the nonspecific effect observed with Tc13Tul and MBP in vivo administration. In the spleen, B-1 and marginal zone B cells have shown to be the main source of T-independent production of IgM antibodies in the early stage of the immune response, although they are also able to 
undergo IgG class switching (Martin et al., 2001). These B lymphocyte subsets, classified as "innate-like" B cells, act as sentinels to rapidly respond to blood-borne antigens by expressing polyreactive less specific B-cell receptors (BCRs) and having rapid proliferation rates (Romero-Ramírez et al., 2019). The basal level of non-specific IgM secretion by splenocytes from $T c 13$ Tul-inoculated mice and the additive effect observed when they are in vitro stimulated with Tc13Tul suggest that the primary immune mechanism triggered by Tc13Tul may include stimulation of innate-like B cells. Although splenocytes of $T c 13$ Tuladministered mice showed increased antibody production, the $\mathrm{B} / \mathrm{T}$ ratios in spleens were not increased at the time of sacrifice $(1.45 \pm 0.0981$ and $1.21 \pm 0.0641$ in MBP- and Tc13Tuladministerd mice, respectively, $p=0.066)$. This could be due to the fact that the i.p. inoculation route could generate a greater immune response in lymph nodes than in the spleen (Schmidt et al., 2016).

In vitro stimulation with $T c 13$ Tul of splenocytes from nä̈ve BALB/c induced IFN- $\gamma$ but not IL-4 or IL-17 secretion. Moreover, the in vivo Tc13Tul administration potentiated the secretion of IFN- $\gamma$ induced by the in vitro Tc13Tul stimulation. Previous studies have shown that in vitro stimulation of splenocytes with TcTS induces secretion of IFN- $\gamma$, IL-6 (Gao et al., 2002) and IL-17 (Bermejo et al., 2013). TcTS has been identified as the sole $T$. cruzi molecule required for an innate-like IL-17 production by B cells, a process that involves TS activity (Bermejo et al., 2013). Therefore, the lack of IL-17 induction by Tc13Tul is an expected result, also due to the absence of Tyr342, which is essential for enzymatic activity. Regarding IFN- $\gamma$, it is known that this cytokine plays an important role in experimental $T$. cruzi infection by inducing macrophage activation, which controls intracellular parasite replication (Gazzinelli et al., 1992). In T. cruzi-infected mice, NK and 
NK T cells are the main source of initial IFN- $\gamma$ production (Cardillo et al., 1996; Duthie et al., 2005). Although splenic IFN- $\gamma$-producing B cells have not yet been studied in T. cruzi infection, they have been identified in mice challenged with several pathogens as Listeria monocytogenes and Escherichia coli (Bao et al., 2014). Thus, it would be interesting to perform further studies to define the population involved in IFN- $\gamma$ production by $T c 13 \mathrm{Tul}$ induction. In relation to the mechanism of IFN- $\gamma$ production by $T c 13 \mathrm{Tul}$, the fact that this antigen also induced IFN- $\gamma$ secretion in naïve splenocytes from $\mathrm{C} 3 \mathrm{H} / \mathrm{HeJ}$ mice suggests that this effect is not mediated by TLR4. This is an interesting result because TLR4 signaling is required for optimal IFN- $\gamma$ production as part of the innate immune response against $T$. cruzi (Oliveira et al., 2010).

In conclusion, our studies support that the possible participation of $T c 13 \mathrm{Tul}$ in the early phase of the immune response against $T$. cruzi is mainly exerted in phenomena related to the evasion of the immune system, such as polyclonal B cell expansion and non-specific Ig production. In contrast, as IFN- $\gamma$ is an important factor involved in the resistance to $T$. cruzi, this effect may be considered in favor to the host. However, it has been suggested that the excess of nitric oxide induced by IFN- $\gamma$ may be involved in down-regulating the immune responses against the parasite (Martins et al., 1999). The mechanism by which Tc13Tul produces these effects was not studied in this work. Affinity assays showed that Tc13Tul binds the B cell surface but also, to a lesser extent, the $\mathrm{T}$ cell surface. As this antigen has no TS activity, a possible hypothesis to be further evaluated is that all these effects could be mediated by the lectin motif present in the amino terminal region of this antigen (Buschiazzo et al., 2002; Todeschini et al., 2002a; Todeschini et al., 2004). In this 
regards, studies on $T c \mathrm{TS}$ have demonstrated its ability to induce stimulatory responses on $\mathrm{T}$ and $\mathrm{B}$ cells through the engagement of host sialylated glycoproteins, such as CD43 and CD45, respectively (Todeschini et al., 2002a,b; Bermejo et al., 2013). Therefore, these molecules are good candidates to take into account for future studies on the mechanism of action of $T c 13 T u l$. 


\section{ACKNOWLEDGMENTS}

MCA and GAG are members of the Research Career of the Consejo Nacional de Investigaciones Científicas y Técnicas of Argentina (CONICET). We specially thank Dr. Susana Laucella for critically reviewing the manuscript.

\section{FINANCIAL SUPPORT}

This work was supported by the Consejo Nacional de Investigaciones Científicas y Técnicas of Argentina (CONICET) (grant PIP 2012-14 n 114-20110100197 to GAG) and the Instituto Nacional de Parasitología “'Dr. Mario Fatala Chaben’'-ANLIS.

\section{ETHICAL STANDARDS}

Animal studies were carried out with the approval of the Institutional Ethical Committee and conformed to the ethical treatment of animals established by the Argentinean Animal Protection Society.

\section{CONFLICTS OF INTEREST}

None 


\section{REFERENCES}

Affranchino JL, Ibañez CF, Luquetti AO, Rassi A, Reyes MB, Macina RA, Aslund L, Pettersson U and Frasch AC (1989). Identification of a Trypanosoma cruzi antigen that is shed during the acute phase of Chagas' disease. Molecular and Biochemical Parasitology 34, 221-228.

Akira S, Uematsu S and Takeuchi O (2006). Pathogen recognition and innate immunity. Cell 124, 783-801.

Alvarez P, Leguizamón MS, Buscaglia CA, Pitcovsky TA and Campetella O (2001). Multiple overlapping epitopes in the repetitive unit of the shed acute-phase antigen from Trypanosoma cruzi enhance its immunogenic properties. Infection and Immunity 69, 79467949.

Andersson J, Coutinho A and Melchers F (1978). The switch from IgM to IgG secretion in single mitogen-stimulated B-cell clones. The Journal of Experimental Medicine 147, 1744-1754.

Aridgides D, Salvador R and Pereira Perrin M (2013). Trypanosoma cruzi coaxes cardiac fibroblasts into preventing cardiomyocyte death by activating nerve growth factor receptor TrkA. PLoS One $\mathbf{8}$, e57450.

Bao Y, Liu X, Han C, Xu S, Xie B, Zhang Q, Gu Y, Hou J, Qian L, Qian C, Han H and Cao X (2014). Identification of IFN- $\gamma$-producing innate B cells. Cell Research 24, $161-176$.

Bermejo DA, Amezcua Vesely MC, Khan M, Acosta Rodríguez EV, Montes CL, Merino MC, Toellner KM, Mohr E, Taylor D, Cunningham AF and Gruppi A (2011). 
Trypanosoma cruzi infection induces a massive extrafollicular and follicular splenic B-cell response which is a high source of non-parasite-specific antibodies. Immunology 132, 123133.

Bermejo DA, Jackson SW, Gorosito-Serran M, Acosta Rodríguez EV, Amezcua Vesely MC, Sather BD, Singh AK, Khim S, Mucci J, Liggitt D, Campetella O, Oukka M, Gruppi A and Rawlings DJ (2013). Trypanosoma cruzi trans-sialidase initiates a program independent of the transcription factors ROR $\gamma \mathrm{t}$ and Ahr that leads to IL-17 production by activated B cells. Nature Immunology 14, 514-522.

Beucher M and Norris KA (2008). Sequence diversity of the Trypanosoma cruzi complement regulatory protein family. Infection and Immunity 76, 750-775.

Bontempi EJ, García GA, Buschiazzo A, Henriksson J, Pravia CA, Ruiz AM, Pettersson U and Pszenny V. (2000). The tyrosine aminotransferase from Trypanosoma rangeli: sequence and genomic characterization. FEMS Microbiology Letters 189, 253-257.

Bryan MA, Guyach SE and Norris KA (2010). Specific humoral immunity versus polyclonal B cell activation in Trypanosoma cruzi infection of susceptible and resistant mice. PloS Neglected Tropical Diseases 4, e733.

Burgos JM, Risso M G, Brenière SF, Barnabé C, Campetella $O$ and Leguizamón MS (2013). Differential distribution of genes encoding the virulence factor trans-sialidase along Trypanosoma cruzi Discrete typing units. PLoS One 8, e58967.

Burns JM Jr, Shreffler WG, Rosman DE, Sleath PR, March CJ and Reed SG (1992). Identification and synthesis of a major conserved antigenic epitope of Trypanosoma cruzi. 
Proceedings of the National Academy of Sciencies of the United States of America 89, 1239-124.

Buscaglia CA, Alfonso J, Campetella O and Frasch AC (1999). Tandem amino acid repeats from Trypanosoma cruzi shed antigens increase the half-life of proteins in blood. Blood 93, 2025-2032.

Buscaglia CA, Campetella O, Leguizamón MS and Frasch AC (1998). The repetitive domain of Trypanosoma cruzi trans-sialidase enhances the immune response against the catalytic domain. The Journal of Infectious Diseases. 177, 431-436.

Buschiazzo A, Amaya MF, Cremona ML, Frasch AC and Alzari PM (2002). The crystal structure and mode of action of trans-sialidase, a key enzyme in Trypanosoma cruzi pathogenesis. Molecular Cell 10, 757-768.

Campetella O, Sánchez D, Cazzulo JJ and Frasch AC (1992). A superfamily of Trypanosoma cruzi surface antigens. Parasitology Today 8, 378-380.

Cardillo F, Voltarelli JC, Reed SG and Silva JS (1996). Regulation of Trypanosoma cruzi infection in mice by gamma interferon and interleukin 10: role of NK cells. Infection and Immunity 64, 128-134.

Cardoso MS, Reis-Cunha JL and Bartholomeu DC (2016). Evasion of the Immune Response by Trypanosoma cruzi during Acute Infection. Frontiers in Immunology 6, 659.

Cremona ML, Sánchez DO, Frasch AC and Campetella O (1995). A single tyrosine differentiates active and inactive Trypanosoma cruzi trans-sialidases. Gene 160, 123-128. 
Cremona ML, Campetella O, Sanchez DO and Frasch AC (1999). Enzymically inactive members of the trans-sialidase family from Trypanosoma cruzi display betagalactose binding activity. Glycobiology 9, 581-587.

Da Silva AC, Espinoza AG, Taibi A, Ouaissi A and Minoprio P (1998). A 24,000 MW Trypanosoma cruzi antigen is a B cell activator. Immunology 94, 189-196.

Duthie MS, Kahn M, White M, Kapur RP and Kahn SJ (2005). Critical proinflammatory and anti-inflammatory functions of different subsets of CD1d-restricted natural killer T cells during Trypanosoma cruzi infection. Infection and Immunity 73, 181192.

Freitas LM, dos Santos SL, Rodrigues-Luiz GF, Mendes TA, Rodrigues TS, Gazzinelli RT, Teixeira SM, Fujiwara RT and Bartholomeu DC (2011). Genomic analyses, gene expression and antigenic profile of the trans-sialidase superfamily of Trypanosoma cruzi reveal an undetected level of complexity. PLOS ONE 6, e25914.

Gao W, Wortis HH and Pereira MA (2002). The Trypanosoma cruzi trans-sialidase is a T cell-independent B cell mitogen and an inducer of non-specific Ig secretion. International Immunology 14, 299-308.

García GA, Joensen LG, Bua J, Ainciart N, Perry SJ and Ruiz AM (2003). Trypanosoma cruzi: molecular identification and characterization of new members of the Tc13 family. Description of the interaction between the Tc13 antigen from Tulahuen strain and the second extracellular loop of the beta(1)-adrenergic receptor. Experimental Parasitology 103, 112-119. 
García GA, Arnaiz MR, Laucella SA, Esteva MI, Ainciart N, Riarte A, Garavaglia

PA, Fichera LE and Ruiz AM (2006). Immunological and pathological responses in BALB/c mice induced by genetic administration of Tc13Tul antigen of Trypanosoma cruzi. Parasitology 132, 855-866.

García GA, Arnaiz MR, Esteva MI, Laucella SA, Garavaglia PA, Ibarra SE and Ruiz AM (2008). Evaluation of immune responses raised against Tc13 antigens of Trypanosoma cruzi in the outcome of murine experimental infection. Parasitology 135, 347-357.

Gazzinelli RT, Oswald IP, Hieny S, James SL and Sher A (1992). The microbicidal activity of interferon-gamma-treated macrophages against Trypanosoma cruzi involves an L-arginine-dependent, nitrogen oxide-mediated mechanism inhibitable by interleukin-10 and transforming growth factor-beta. European Journal of Immunology 22, 2501-2506.

Gupta S, Govil D, Kakar PN, Prakash O, Arora D, Das S, Govil P and Malhotra A (2009). Colistin and polymyxin B: a re-emergence. Indian Journal of Critical Care Medicine 13, 49-53.

Leguizamón MS, Mocetti E, Garcia Rivello H, Argibay P and Campetella O (1999). Trans-sialidase from Trypanosoma cruzi induces apoptosis in cells from the immune system in vivo. The Journal of Infectious Diseases 180, 1398-1402.

Liu G, Zhang Y, Zhang N, Ni W, Jie J, Jiang L and Tai G (2017). Escherichia coli maltose-binding protein (MBP) activates mouse Th1 through TLR2-mediated MyD88dependent pathway and TLR4-mediated TRIF-dependent pathway. International Immunopharmacology 50, 338-344. 
Martin DL, Weatherly DB, Laucella SA, Cabinian MA, Crim MT, Sullivan S, Heiges

M, Craven SH, Rosenberg CS, Collins MH, Sette A, Postan M and Tarleton RL

(2006). CD8 + T-cell responses to Trypanosoma cruzi are highly focused on strain-variant trans-sialidase epitopes. PLoS Pathogens 2, e77.

Martin F, Oliver AM and Kearney JF (2001). Marginal zone and B1 B cells unite in the early response against T-independent blood-borne particulate antigens. Immunity 14, 617629.

Martins GA, Vieira LQ, Cunha FQ and Silva JS (1999). Gamma interferon modulates CD95 (Fas) and CD95 ligand (Fas-L) expression and nitric oxide-induced apoptosis during the acute phase of Trypanosoma cruzi infection: a possible role in immune response control. Infection and Immunity 67, 3864-3871.

Millar AE, Wleklinski-Lee M and Kahn SJ (1999).The surface protein superfamily of Trypanosoma cruzi stimulates a polarized Th1 response that becomes anergic. Journal of Immunology 162, 6092-6099.

Minoprio P, Burlen O, Pereira P, Guilbert B, Andrade L, Hontebeyrie-Joskowicz M, Coutinho A (1998). Most B cells in acute Trypanosoma cruzi infection lack parasite specificity. Scandinavian Journal of Immunology 28, 553-561.

Miyawaki T, Uehara T, Nibu R, Tsuji T, Yachie A, Yonehara S and Taniguchi N (1992). Differential expression of apoptosis-related Fas antigen on lymphocyte subpopulations in human peripheral blood. Journal of Immunology 149, 3753-3758. 
Mucci J, Risso MG, Leguizamón MS, Frasch AC and Campetella O (2006). The transsialidase from Trypanosoma cruzi triggers apoptosis by target cell sialylation. Cellular Microbiology 8, 1086-1095.

Mucci J, Lantos AB, Buscaglia CA, Leguizamón MS and Campetella O (2017). The Trypanosoma cruzi surface a nanoscale patch work quilt. Trends in Parasitology 33, 102112.

Nowell PC (1960). Phytohemagglutinin: an initiator of mitosis in culture of animal and human leukocytes. Cancer Research 20, 462-466.

Oliveira AC, de Alencar BC, Tzelepis F, Klezewsky W, da Silva RN, Neves FS, Cavalcanti GS, Boscardin S, Nunes MP, Santiago MF, Nóbrega A, Rodrigues MM and Bellio M (2010). Impaired innate immunity in Tlr4(-/-) mice but preserved CD8+ T cell responses against Trypanosoma cruzi in Tlr4-, Tlr2-, Tlr9- or Myd88-deficient mice. PloS Pathogens 6, e1000870.

Ouaissi A, Guilvard E, Delneste Y, Caron G, Magistrelli G, Herbault N, Thieblemont N and Jeannin P (2002). The Trypanosoma cruzi Tc52-released protein induces human dendritic cell maturation, signals via Toll-like receptor 2, and confers protection against lethal infection. Journal of Immunology 168, 6366-6374.

Peralta JM, Teixeira MG, Shreffler WG, Pereira JB, Burns JM Jr, Sleath PR and Reed SG (1994). Serodiagnosis of Chagas disease by enzyme-linked immunosorbent assay using two synthetic peptides as antigens. Journal of Clinical Microbiology 32, 971-974. 
Poltorak A, He X, Smirnova I, Liu MY, Van Huffel C, Du X, Birdwell D, Alejos E, Silva M, Galanos C, Freudenberg M, Ricciardi-Castagnoli P, Layton B and Beutler B (1998). Defective LPS signaling in C3H/HeJ and C57BL/10ScCr mice: mutations in Tlr4 gene. Science 282, 2085-2088.

Rassi A Jr, Rassi A and Marin-Neto JA (2010). Chagas disease. Lancet 375, 1388-402.

Reina-San-Martin B, Degrave W, Rougeot C, Cosson A, Chamond N, Cordeiro-DaSilva A, Arala-Chaves M, Coutinho A and Minoprio P (2000). A B cell mitogen from a pathogenic trypanosome is a eukaryotic proline racemase. Nature Medicine 6, 890-897.

Romero-Ramírez S, Navarro-Hernandez IC, Cervantes-Díaz R, Sosa-Hernández VA, Acevedo-Ochoa E, Kleinberg-Bild A, Valle-Rios R, Meza-Sánchez DE, HernándezHernández JM and Maravillas-Montero JL (2019). Innate-like B cell subsets during immune responses: Beyond antibody production. Journal of Leukocyte Biology 105, 843856.

Salvador R, Aridgides D and Pereira Perrin M (2014). Parasite-derived neurotrophic factor/trans-sialidase of Trypanosoma cruzi links neurotrophic signaling to cardiac innate immune response. Infection and Immunity 82, 3687-3696.

Santamaría AL, De Rissio AM, Riarte A, Garavaglia PA, Bruballa AC, Rodríguez MA, Irazu LE, Ruiz AM and García GA (2013). Use of an enzyme-linked immunosorbent assay that utilizes the Tc13Tul antigen of Trypanosoma cruzi to monitor patients after treatment with benznidazole. Diagnostic Microbiology and Infectious Disease 76, 197-205. 
Schmidt ST, Khadke S, Korsholm KS, Perrie Y, Rades T, Andersen P, Foged C and

Christensen D (2016). The administration route is decisive for the ability of the vaccine adjuvant CAF09 to induce antigen-specific CD8(+) T-cell responses: The immunological consequences of the biodistribution profile. Journal of Controlled Release 239, 107-117.

Sharon N and Lis H (2004). History of lectins: from hemagglutinins to biological recognition molecules. Glycobiology 14, 53R-62R.

Todeschini AR, Girard MF, Wieruszeski JM, Nunes MP, DosReis GA, Mendonça-

Previato L and Previato JO (2002a). trans-Sialidase from Trypanosoma cruzi binds host T-lymphocytes in a lectin manner. The Journal of Biological Chemistry 277, 45962-45968.

Todeschini AR, Nunes MP, Pires RS, Lopes MF, Previato JO, Mendonça-Previato L and DosReis GA (2002b). Costimulation of host T lymphocytes by a trypanosomal transsialidase: involvement of CD43 signaling. Journal of Immunology 168, 5192-5198.

Todeschini AR, Dias WB, Girard MF, Wieruszeski JM, Mendonça-Previato L and Previato JO (2004). Enzymatically inactive trans-sialidase from Trypanosoma cruzi binds sialyl and beta-galactopyranosyl residues in a sequential ordered mechanism. The Journal of Biological Chemistry 279, 5323-5328.

Tu W, Cheung PT and Lau YL (2000). Insulin-like growth factor 1 promotes cord blood $\mathrm{T}$ cell maturation and inhibits its spontaneous and phytohemagglutinin-induced apoptosis through different mechanisms. Journal of Immunology 165, 1331-1336. 
WHO-World Health Organization (2015). Chagas Disease in Latin America: An Epidemiological Update Based on 2010 Estimates. Geneva: WHO. http://www.who.int/wer/2015/wer9006.pdf?ua=1 (accessed 3 September 2018).

Wrightsman RA, Dawson BD, Fouts DL and Manning JE (1994). Identification of immunodominant epitopes in Trypanosoma cruzi trypomastigote surface antigen-1 protein that mask protective epitopes. Journal of Immunology 153:3148-3154. 


\section{FIGURE LEGENDS}

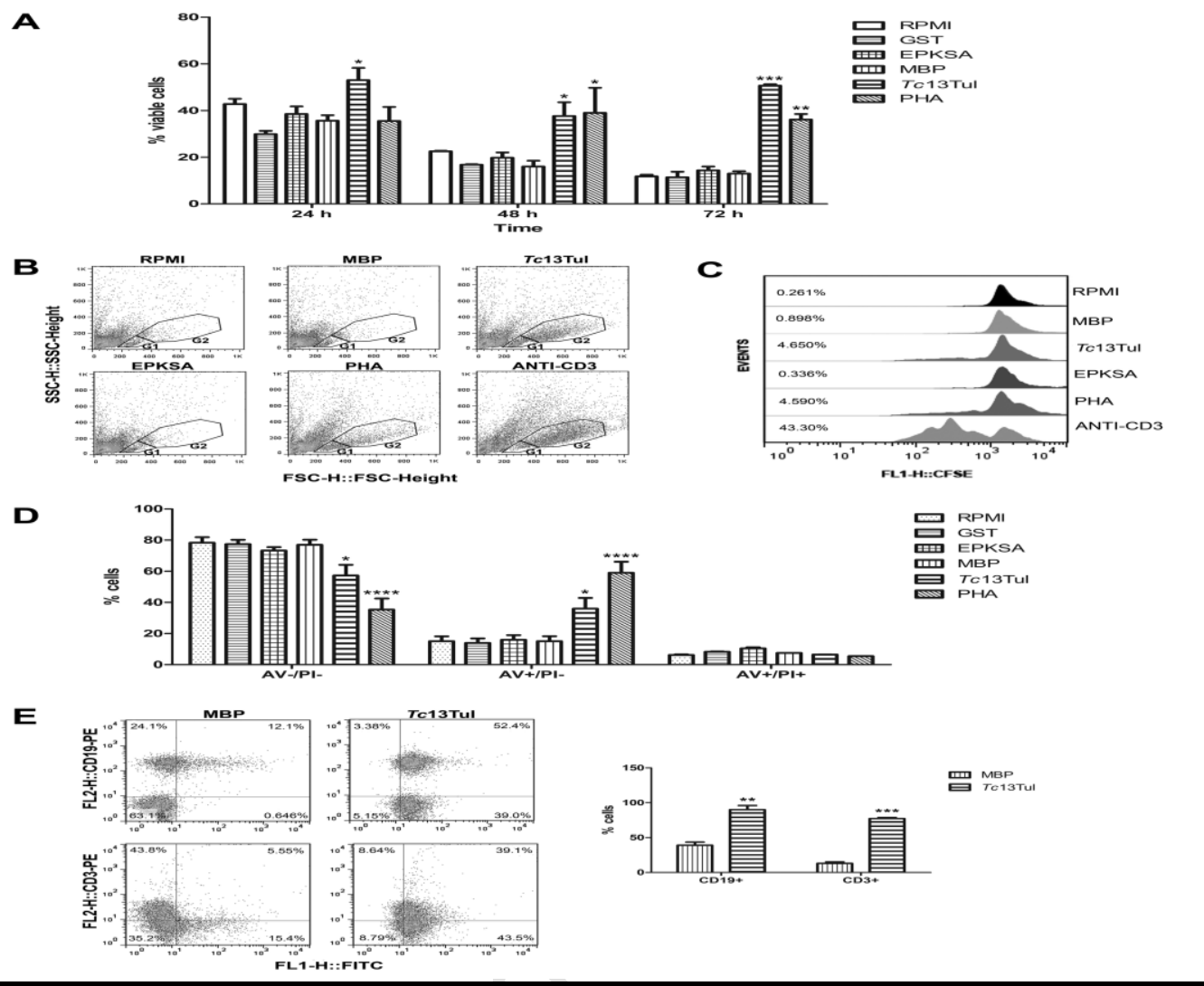

Figure 1: Effect of $T c 13 T u$ on the viability of in vitro cultured splenocytes from naïve BALB/c mice and their lymphocyte population.

Splenocytes were cultured for the indicated times with $T c 13 \mathrm{Tul}\left(6 \mu \mathrm{g} / 10^{6}\right.$ cells), EPKSA (6 $\mu \mathrm{g} / 10^{6}$ cells) or the equivalent amounts of their respective carrier proteins, MBP $(2.2$ $\mu \mathrm{g} / 10^{6}$ cells) and GST $\left(1.5 \mu \mathrm{g} / 10^{6}\right.$ cells). Cells cultured in the absence of stimulus (RPMI) and in the presence of PHA $\left(1.25 \mu \mathrm{g} / 10^{6}\right.$ cells) or anti-CD3 monoclonal antibody (10 $\mu \mathrm{g} / \mathrm{ml}$ ) were used as controls. (A) Surviving cells were evaluated by the trypan blue exclusion assay and analyzed by optical microscopy. The initial cell inoculum of $2 \times 10^{6}$ cells/ml was considered as $100 \%$ of viable cells. (B) Splenocytes stimulated with the antigens for $72 \mathrm{~h}$ were analyzed by flow cytometry. Lymphocytes were gated based on 
forward scattering (FSC-H) and side scattering (SSC-H). Populations of basal (G1) and enlarged (G2) lymphocytes are indicated in the dot plots. (C) Splenocytes were stained with CFSE prior to stimulation, stimulated with antigens for $72 \mathrm{~h}$ and analyzed by flow cytometry. Histograms of CFSE-stained cells in the gated population G1+G2 showing the percentages of divided cells calculated with the FlowJo Proliferation Tool. (D) After $48 \mathrm{~h}$ of stimulation, splenocytes were double-stained with annexin V-FITC (AV) and propidium iodide (PI) and analyzed by flow cytometry in the gated population G1+G2. (E) Splenocytes from naïve BALB/c mice were incubated with FITC-Tc13Tul or FITC-MBP, subsequently stained with anti-CD19-PE or anti-CD3-PE and analyzed by flow cytometry gated on lymphocyte population. Dot plots (CD19+ and CD3+) of FITC-stained lymphocytes and their quantification are shown. Representative data of at least two independent experiments are shown. Data are the means + SE. Significance was determined by two-way ANOVA and Bonferroni as post-test. *, $p<0.05, * *, p<0.01, * * *, p<0.001$ and ****, $\mathrm{p}<0.0001$ respect to negative controls (RPMI, MBP and/or GST). 
A
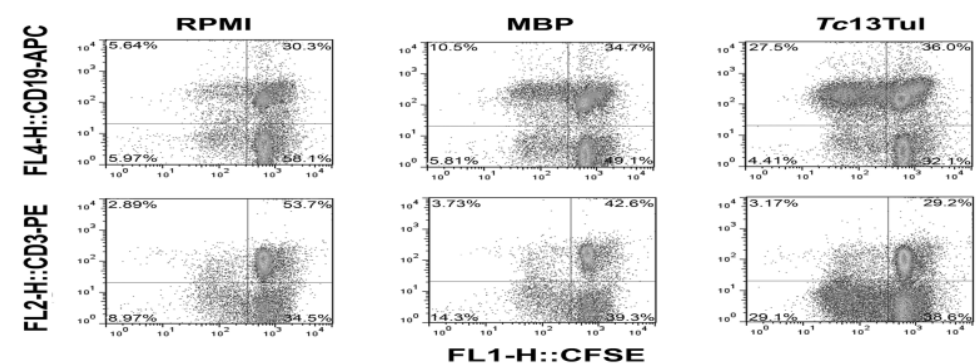

B

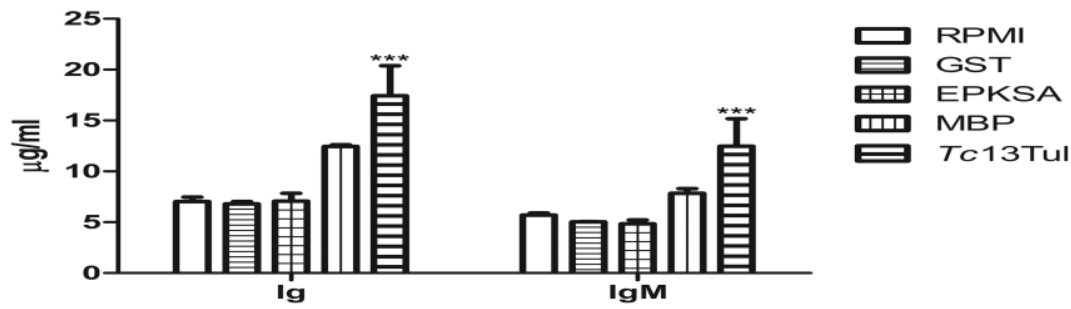

C

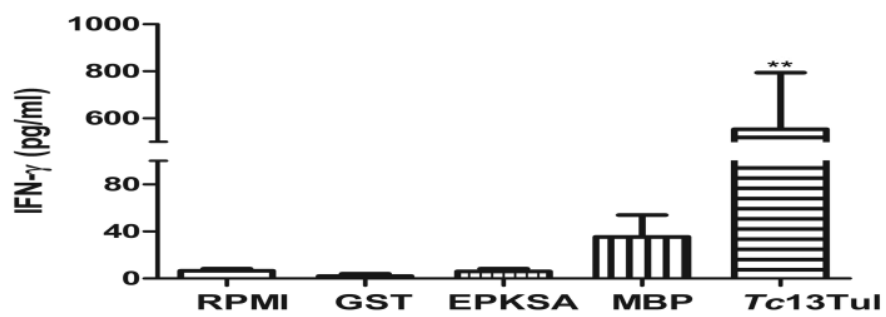

D

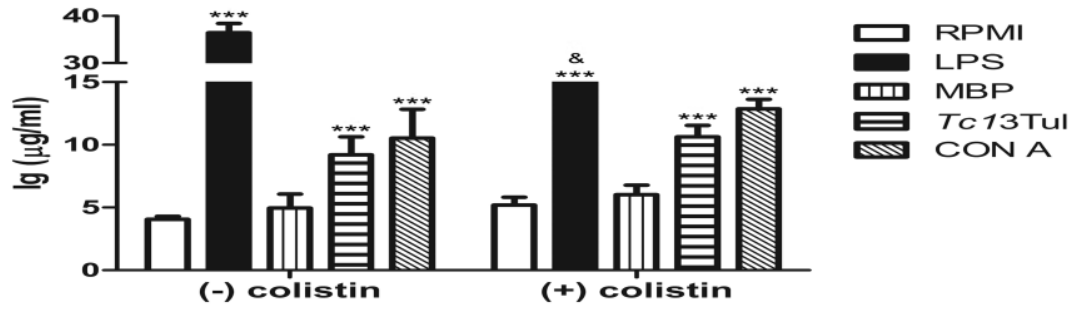

Figure 2: Effect of Tc13Tul on lymphocyte proliferation, polyclonal Ig and IFN- $\gamma$ secretion in cultured splenocytes from nä̈ve BALB/c mice.

Splenocytes were stained with CFSE and cultured for $72 \mathrm{~h}$ with $T c 13 \mathrm{Tul}\left(6 \mu \mathrm{g} / 10^{6}\right.$ cells $)$, MBP $\left(2.2 \mu \mathrm{g} / 10^{6}\right.$ cells) or medium (RPMI). After stimulation, cells were stained with antiCD19-APC and anti-CD3-PE and analyzed by flow cytometry. (A) Dot plots showing double-stained (CFSE/CD19-APC and CFSE/CD3-PE) cells on lymphocyte gate. (B) Total Ig and IgM secretion evaluated by ELISA in splenocyte supernatants. (C) IFN- $\gamma$ secretion evaluated by ELISA in splenocyte supernatants. $* *, p<0.01$ and $* * *, p<0.001$ respect to 
negative controls (RPMI, MBP and/or GST). (D) Total Ig secretion evaluated by ELISA in supernatants of splenocytes induced for $72 \mathrm{~h}$ with the antigens (MBP or Tc13Tul), lipopolysaccharide (LPS) $(5 \mu \mathrm{g} / \mathrm{ml})$ or concanavalin A (CON A) $(10 \mu \mathrm{g} / \mathrm{ml})$ in the absence or presence of colistin $(10 \mu \mathrm{g} / \mathrm{ml})$, an agent which interferes with LPS activity. Representative data of at least two independent experiments are shown. Data are the means + SE. Significance was determined by ANOVA and Bonferroni as post-test. ***, $p<0.001$ respect to negative controls (RPMI, MBP and/or GST) and \&, $\mathrm{p}<0.01$ compared with absence of colistin. 
A

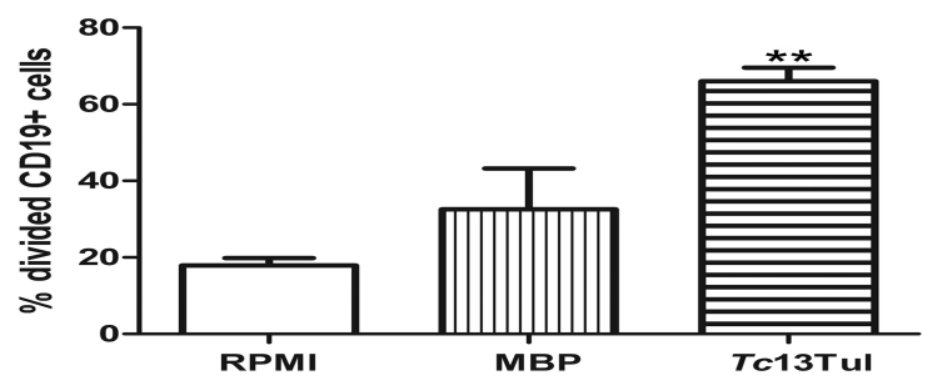

$\mathbf{B}$

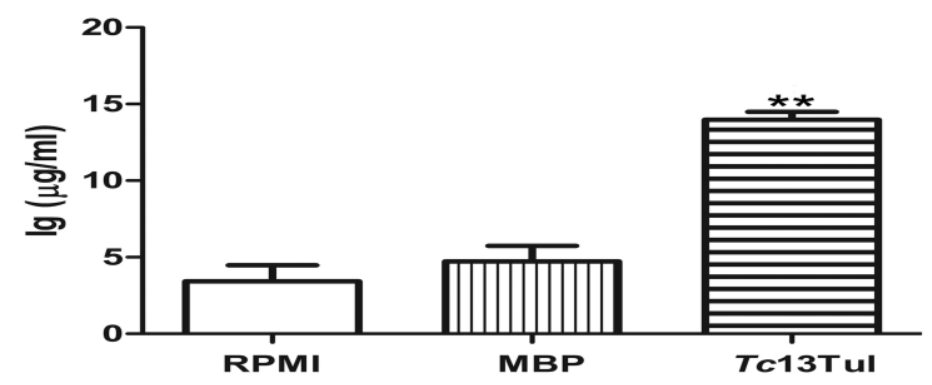

C

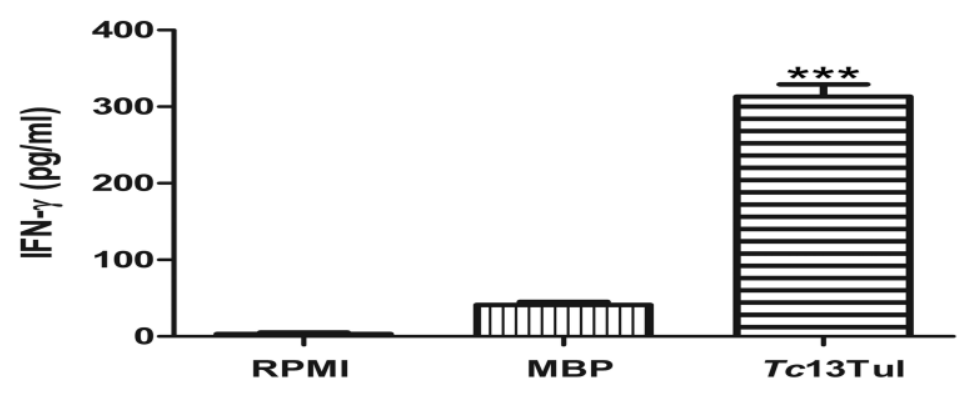

Figure 3: Effect of Tc13Tul in cultured nä̈ve splenocytes from the LPS-resistant $\mathrm{C} 3 \mathrm{H} / \mathrm{HeJ}$ mouse strain

Splenocytes from naïve $\mathrm{C} 3 \mathrm{H} / \mathrm{HeJ}$ mice were stained with CFSE and cultured for $72 \mathrm{~h}$ with Tc13Tul $\left(6 \mu \mathrm{g} / 10^{6}\right.$ cells), MBP $\left(2.2 \mu \mathrm{g} / 10^{6}\right.$ cells) or medium (RPMI). (A) After stimulation, cells were stained with anti-CD19-PE and proliferation of CD19+ cells was analyzed by flow cytometry on lymphocyte gate. The percentage of divided cells was calculated with the FlowJo Proliferation Tool. (B) Total Ig and (C) IFN- $\gamma$ evaluated in 
splenocyte supernatants by ELISA. Representative data of at least two independent experiments are shown. Data are the means + SE. Significance was determined by one-way ANOVA and Bonferroni as post-test. **, $p<0.01$ and ***, $p<0.001$ respect to RPMI and MBP.

A

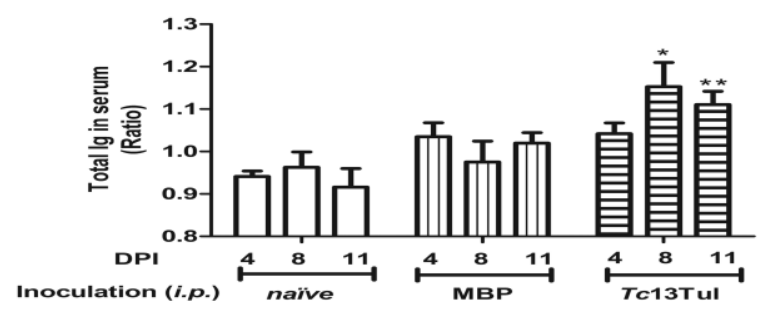

B

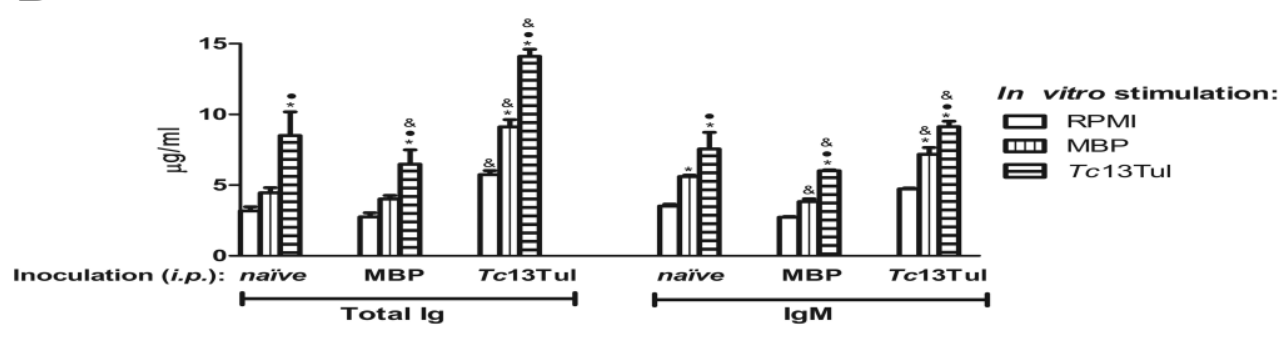

C

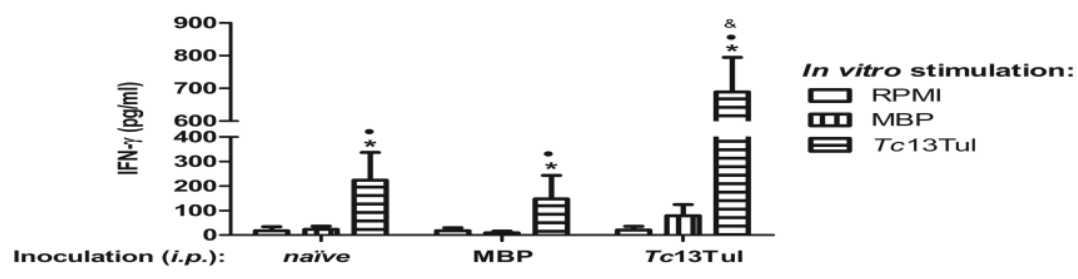

Figure 4: Effect of Tc13Tul after in vivo administration to naïve BALB/c mice.

(A) Total Ig levels evaluated by ELISA in mouse sera injected with buffer (naïve) and inoculated with MBP or Tc13Tul (a daily i.p. dose of $1 \mu \mathrm{g} /$ mouse for three days). Sera were collected for evaluation prior to the injection and 4, 8 and 11 days post-injection (DPI). Individually for each mouse $(n=3)$, the ratio between Ig amounts in serum at the indicated days and their amounts prior to antigen injection was calculated. $*, p<0.05$ and $* *, p<0.01$ 
respect to the naïve group. (B) Total Ig and IgM and (C) IFN- $\gamma$ levels in supernatants of pooled splenocytes from naïve, MBP- and Tc13Tul-inoculated mice cultured in vitro for 72 h without stimulation (RPMI) or stimulated with MBP or $T c 13$ Tul. * and $\bullet, p<0.05$ respect to in vitro cultured splenocytes without stimulation and stimulated with MBP, respectively. $\&, p<0.05$ respect to splenocytes from naïve mice. Data represent the means $+\mathrm{SE}$. Significance was determined by two-way ANOVA and Bonferroni as post-test. 